Journal of International Students । 188

Peer-Reviewed Article

ISSN: 2162-3104 Print/ ISSN: 2166-3750 Online

Volume 5, Issue 2 (2015), pp. 188-200

(C) Journal of International Students

http://jistudents.org

\title{
U.S. Higher Education Classroom Experiences of Undergraduate Chinese International Students
}

\author{
Gabriela Valdez (Doctoral Candidate) \\ Department of Language, Reading and Culture \\ The University of Arizona (USA)
}

\begin{abstract}
The purpose of this study was to explore undergraduate Chinese international students' perceptions about their classroom experiences in the United States institutions of higher education. Double consciousness, introduced by W.E.B. Du Bois, was used as the theoretical framework for this study. After analyzing the 15 interviews to Chinese international students, the following areas were discussed: comparison of classroom experiences in the United States and China; positive and negative classroom practices in the U.S.; perceptions of the way American faculty and students perceived Chinese international students; and double consciousness of Chinese international students. While most of the participants preferred the American classroom practices over practices in China, their perceptions about the way American students and faculty perceived them were conflicting. The concept of double consciousness also helped to illustrate the internal identity conflict of being Chinese and being "Americanized."
\end{abstract}

Keywords: Chinese students, classroom experiences, identity, international students, assumptions, perceptions

The United States attracted 819,644 international students who enrolled in American institutions of higher education during the academic year 2012-2013 according to the Open Doors report (Institute of International Education [IIE]). This number represents a 7.2\% increase from the previous academic year and placed the United States as the country with the most international students around the world (Choudaha, Chang, \& Kono, 2013). China has been the top country of origin since 2004, sending the largest number of international students around the world to English speaking countries such as the U.S., Australia, the U.K., and Canada (Choudaha et al., 2013). This phenomenon was also observed in enrollment in the United States where 235,597 Chinese international students, the largest group of international students, studied during the academic year 2012-2013. Chinese students were followed by students from India with 96,754

Summer 2015

http://jistudents.org

Volume $5 \bullet$ Issue 2 
students and students from South Korea with 70,627 that attended institutions of higher education in the United States (IIE, 2013). The increasing number of undergraduate Chinese students, especially in the fields of business and engineering, is drawing attention from higher education administrators; however, researchers and administrators have paid little attention to classroom experiences of international students, especially Chinese students.

What causes international student mobility? One of the factors affecting this increase in international student mobility is the gap between the educational supply and demand of many countries of origin. It was estimated that in 2006 there were around 3,000 Chinese institutions of higher education serving approximately 25.4 million students (The International Comparative Higher Education Finance and Accessibility Project, 2009). China has currently the largest higher education system in the world, but only $2.5 \%$ of China's population has access to this educational system.

Access to economic resources is something that also influences the number of students who have the opportunity to study abroad; as an example, it was estimated that in 2006 about $15 \%$ of China's population was considered middle class and had access to resources, nearly 201,619,500 people (Chen \& Lu, 2006). The economic affluence of millions of people may impact international student mobility, not to mention the apparent prestige that comes with studying in the U.S., something that is often perceived as a benefit by families of international students. A study conducted about Chinese students study abroad decision-making also supports some of these causes arguing that students' social influences, perceived high educational quality in specific countries and social-economic pragmatism from China-based research are among the factors that influence Chinese student's decisions to study abroad and their choice of institution (Liu, Elston, \& Zhou, 2013). Similarly, these factors might influence Chinese students' perceptions about their classroom experiences in the U.S.

Studies published and accessible using three major search engines, namely ERIC, Google Scholar and JSTOR about the classroom experiences of Chinese students in English speaking countries include those in New Zealand (Holmes, 2006), in Canada (Zhou, Knoke, \& Sakamoto, 2005), and in Britain (Wang \& Byram, 2011), but few studies have been published specifically about classroom experiences of Chinese students in the United States (Hsieh, 2007, Wan, 1999). The purpose of this study is to address the gap in the literature about Chinese students' experiences in the U.S. higher education system by examining Chinese international students' perceptions about their classroom experiences using a double consciousness framework. I also intend to further explore the students' perceptions about classroom participation, sharing indigenous Chinese knowledge in U.S. classrooms, and the way American faculty and American students perceive Chinese students.

The following research questions will guide this study:

- What are some similarities and differences between classroom experiences in the U.S. and China according to participants?

- What U.S. classroom practices are perceived as positive by participants? What U.S. classroom practices are perceived as negative?

- What are the participants' perceptions about the way American faculty and students perceive Chinese students?

- What part does "double consciousness" play in the classroom experiences of Chinese international students? 


\section{Theoretical Framework}

The concept of double consciousness was used as the theoretical framework for this study. W.E.B. Du Bois first introduced the concept of double consciousness in 1897 in his essay Striving of the Negro People when he referred to an African American's experience of "twoness" or the experience of being American and Black at the same time, two identities in conflict, according to Du Bois. This concept was also described by Du Bois as a "sense of always looking at one's self through the eyes of others..." (Du Bois, 1897) as he explored his own identity and the identity of African Americans as a group. Over the years this theory has been applied in different fields such as education (Lee, 1990), cultural studies (Dayal, 1996), and literature (Adell, 1994). Du Bois' work has also influenced current theories such as critical race theory, which explores power relations and, whiteness studies which explores white ideology and its invisibility in society.

This study addresses three different issues, previously identified by Dickson (1992), related to the concept of double consciousness: the power of white stereotypes in the lives and thoughts of people of color, the double consciousness created by practical racism, and finally, the internal double consciousness conflict in the individual. Although Dickson (1992) did not apply the concept of double consciousness to Chinese international students, his work represents a relevant analysis of Du Bois' model of double consciousness.

For the purpose of this article, I argue that Chinese international students experienced a double consciousness while they identified with other Chinese international students, but also tried to disassociate themselves from behaviors which were not generally perceived as positive by U.S. faculty members and students. This study addresses the power of white stereotypes in the lives of the participants, the double consciousness created by practical racism that excludes participants from classroom participation, and students' individual double consciousness conflict. It is important to clarify that the intention of the use of double consciousness for this article is not to compare the experiences faced by African Americans and Chinese international students, but rather to explore specifically the classroom experiences of Chinese international students through a critical lens that offers a better understanding of this growing population in institutions of higher education in the United States.

\section{Literature Review}

The number of studies published about international students' perceptions of classroom experiences in the United States is limited, especially those that concern Chinese international students. A few researchers, whose work is accessible using three major search engines, namely ERIC, Google Scholar and JSTOR (Chu \& Kim, 1999; Heggins \& Jackson, 2001; Kim, 2012; Lee, 2009; Liberman, 1994; Major, 2005) have explored the perceptions of Asian students studying in the United States, but only two, a case study by Hsieh (2007) and a case study by Wan (1999), have explored the perception of Chinese students specifically about their classroom experiences in the U.S. The limitation of only two relevant published studies is that the other literature examined, although focusing on Asian students in general, will still have to be carefully generalized to the Chinese international student population.

Of those studies that explored the perceptions of Asian students, including Chinese international students, in the U.S. higher education system, themes of identity change and selfperception appeared consistently in three of them (Chu \& Kim, 1999; Hsieh, 2007; Kim, 2012). 
For example, Kim (2012) explored students' identities and self-perceptions in a study that focused on the experiences of 50 Korean graduate students in the United States. In interviews, students expressed a sense of inferiority compared to American graduate students because of their English language ability. A relevant part of Kim's analysis is the exploration of the development of a new identity of inferiority by Korean students studying in the U.S. This development started with their classroom experiences, in which these formerly high-achieving students quickly learned that they did not have the language ability to perform at the level they were accustomed to in their Korean universities. Students used phrases such as "I now accept my limitations" and "handicap" as ways to describe their new self-image when they compared their classroom performance to that of their American counterparts. Kim (2012) attributed this new identity of inferiority to a series of negative experiences in the students' academic careers in the U.S.

In a case study by Hsieh (2007), the author explored one Chinese female student's experience in American classrooms. One of the strengths of a case study when applied to educational research is the type of in-depth information that a researcher can collect from one participant. Conversely, some of the weaknesses are its reliability, validity, and generalizability (Merriam, 2009). Similarly to Kim's (2012) findings, the participant in Hsieh's study expressed that she felt invisible and ignored by American students because of her silence during class.

...you know, like a group of American students and you are the only foreigner in that group, then you become like isolated, and you become ignored; you cannot get into their groups or their conversations. I think this is very frustrating... (Hsieh, 2007, p. 384).

According to Hsieh (2007), the participant internalized a deficient self-perception as a useless person in group discussion. The author also observed that the participant perceived that American students attributed this deficiency to her.

Another relevant finding is the importance of students' social networks, especially those formed with other students from the same home country. As an illustration, in the study by Heggins and Jackson (2003), influencing factors were identified after the researchers recruited Asian international students from a Vietnamese Student Organization at a U.S. university. After individually interviewing 28 students and creating two focus groups of 10 students, researchers determined that difficulties adapting to the campus environment often influenced the students' comfort levels and feelings of marginalization in school. The researchers also identified social networks as a way to mediate these adjustment problems.

In a study by Major (2005), the author explored co-national support and the adjustment of Asian students in U.S. higher education institutions. A network of compatriots was identified by participants as their main source of mentoring and cross-cultural reference. One student expressed, “... I was on probation... so my [Taiwanese] friends help me choose. I chose some easy and some hard classes. I worked very hard the second semester. My GPA is 3.09 this semester" (Major, 2005, p. 89). This quote illustrates Major's (2005) claim about the importance of co-national mentoring in the transition from cultural divergence to the adjustment state.

The themes of identity change and self-perception present in the published studies regarding international Asian and Chinese students served as a foundation for the analysis of the data collected for this study. One of the purposes of this present study is to further explore these themes and pay special attention to the role that double consciousness play in the formation of identity and self-perception. 


\section{Research Method}

Undergraduate students from two Chinese student organizations in a large university in the U.S. southwest were invited to participate. After the interview, students were asked to recommend other Chinese students to participate in the study using a snowball sample system. Most of the students recommended were not part of the two student organizations. A total of 15 students voluntarily participated in a 20-30 minute interview. The number of participants in this study represented less than one percent of the estimated 1,613 Chinese international undergraduate and graduate student population in that specific university. Redundancy of information collected during the interviews was used to determine the size of the participant sample. Thirteen participants were majoring in business, one participant was majoring in engineering, and one participant was majoring in retail and consumer science at the time of the interview. This distribution of majors is consistent with the university's Chinese international student population where the majority of Chinese students pursue degrees in business. Similarly, the participants' choice of major is also consistent with the distribution of majors among the overall international student population studying in the United States (IIE, 2013). Participants were in different stages of their undergraduate program, which included five sophomores, seven juniors, and three seniors. Students' times since arrival to the U.S. varied from one year for the student with the most recent arrival to six years with the student with the longest stay in the U.S.

Interviews were conducted in English, which was the participants' second or third language. Participants' English language abilities varied; as an example, the lowest TOEFL score, a test that measures the students' abilities to read, write, and listen in English, reported by the participants was 68 and the highest was 98 with an average TOEFL score of 81.5, on a scale from 0 to 120 (ETS, 2014). It is important to mention that the time when TOEFL tests were taken by participants also varied and TOEFL scores may not have been a fair representation of the participants' current English abilities at the time of the interviews.

I conducted all the interviews and as a second language speaker of English I found that it was beneficial for collecting data as many of the participants expressed comfort communicating in English with someone else whose English was not their first language. It is possible that the students did not feel judged about their language abilities as they recognized my English fluency was not at a native level. I believe this second language commonality granted me access to the international student population. Also, my experience being an international student during my undergraduate years may have affected the way data was collected, analyzed and interpreted. At the same time, it is important to recognize the potential bias that members of a specific student organization might have and how this could have affected the data. I am not a member of the group being studied, but I had established a strong working relationship with some of the students being interviewed as we have collaborated on other projects in the past.

A set of 16 questions (appendix 1) guided the interviews with the students. These questions were used to explore the Chinese international students' perceptions about classroom experiences in the U.S. The interviews were recorded and later transcribed to facilitate analysis. The data analysis stage was conducted using a qualitative analysis software called ATLAS.ti. This software was used to open code the interviews, generate themes, create semantic networks and interpret the results. 


\section{Results and Discussion}

For the purpose of this study, classroom practices in institutions of higher education in the United States are identified as a group of activities that take place in a classroom setting. These activities include, but are not limited to, classroom discussions, teamwork, presentations, and lectures. Engaging classroom practices facilitate meeting class objectives and goals while fostering an interactive learning environment for students. In the case of Chinese international students, inclusion in these classroom practices is essential for their successful education in the U.S.

After analyzing the interviews, the following themes emerged: comparison of classroom experiences in the United States and China, positive and negative classroom practices in the U.S., perceptions of the way American faculty and students perceived Chinese international students, and double consciousness of Chinese international students.

\section{Comparison of classroom experiences in the United States and China}

The majority of the participants compared their undergraduate classroom experiences in the U.S. to those experiences they had in high school in China, as most of them had never attended college in China. The perceptions of classroom experiences in the United States were similar among participants. All of them agreed that they prefer the "more active" teaching style in the U.S., as it was described by one of the participants: "Teaching style in here [U.S.] is more like discussion based, there are often times when we have group discussion, group homework, group project, whereas in China is more like spoon-feeding." The participant referred to spoonfeeding when the instructor tells students exactly what to do, such as when to take notes, and forces them to memorize information.

Another difference between U.S. and China classroom experiences was the ability of students to ask questions during class in the U.S. Six students said that in China, students are not allowed to ask questions. One student went further and added, "In China, generally, I don't go to professors' office hours or ask questions because they give you plenty of instructions, more than you really need to know, so you don't have to go to their office hours." When participants were asked about attending professors' office hours in the U.S., the majority said that they only go to office hours if they are worried about their grades and they mostly talk about their grades. One participant highlighted the difference that "here in the U.S. professors and students are more like friends." All participants also agreed that students who ask questions and talk in class are the ones that get the most attention from the professor in the U.S. classroom setting, something that usually does not happen in a Chinese classroom.

The students' perceptions about sharing knowledge and examples from China in the U.S. classrooms was also discussed. Half of the participants said that they have shared examples from China during their classes in the U.S., but the majority of them said it was either during a class with international focus or when the professor had international experience, and he or she was interested in their perspectives. The other half of the participants said that they have not shared any examples from China during their classes. One participant mentioned that the classes he has taken do not relate to China at all. Three other participants said that sharing examples from China in a U.S. classroom setting was inappropriate. One student expressed the following:

It would be inappropriate [to share examples from China] because we have different cultures, ideas and different ethical standards, and if I bring this up in a huge class, it 
would cause a huge discussion and sometimes, I think, it's impolite to do this during class.

Similarly, another student added, "I definitely share my experience, but not from China because I think if you always talk about the Chinese stuff and it might sound like fresh air [fresh perspective] to the class. Sometimes we need to see the problems globally." The participant's explanation suggests that for him, seeing and discussing a problem with a U.S. perspective is seen as a global perspective. For this group of participants attending institutions of higher education in the U.S. has provided them the opportunity to be able to compare their experiences in both countries.

\section{Classroom practices in the United States}

Classroom practices perceived as positive. Among the classroom practices that were perceived as positive, one in particular was mentioned multiple times by different interviewees, which was peer collaboration. This has been previously referred to as Zone of Proximal Development (ZPD), one of the main concepts of sociocultural theory. This concept was founded on the notion of the existence of an area in which learners, who are cognitively ready, are able to develop fully by interacting with more experienced peers (Vygotsky, 1978). Some researchers have written about the importance of peer collaboration between American students and international students and all the benefits associated with these interactions such as language development, and cultural understanding (Valdez, 2015). Students mentioned the benefits of assigned seats because it gives them the opportunity to interact with other students. A student expressed her opinion by saying, "In my business classes I tend to have side discussion with my friend because we are kind of allowed to do so... and it helps me to learn because sometimes the teacher can't explain as well as my peer does because we think the same way." This quote is a good example of ZPD and the way this student perceived peer collaboration in class.

The majority of students also said that they like oral presentations and group discussions because it gives them an opportunity to talk and practice their English language and get feedback from their peers. One of the participants mentioned:

I really like it [classroom discussion] because it is a way to express your opinion and also it is more like than just sitting in the lecture and listening to the teacher and hear what they are saying. Actually you have interaction with the teacher and the students, so that would make you more understand the materials.

This statement illustrates the student's appreciation of a more interactive classroom setting and at the same time, it indicates that the student values interaction with teachers and students.

Classroom practices perceived as negative. Those practices that were perceived as culturally insensitive were identified as negative by participants. A student gave an example of having to play the game "Who Am I?" where a paper with a name of an American celebrity was placed on her back, and she had to figure out the name of the celebrity by asking questions. When the participant was explaining the game, she said, "Many Chinese students did not get it. I feel very awkward in that game because I don't know the names of the [American] celebrities." 
She went on and added, "I don't feel comfortable with cultural activities because I lack of this culture. I feel awkward." This exemplifies many of the assumptions made by professors about common knowledge in class. Similarly, it illustrates a heavy focus on U.S. culture and lack of inclusion of other cultures in classroom practices. I argue that experiences like these can contribute to the internal double-consciousness conflict of Chinese international students.

Students also identified having a high emphasis on oral participation as negative when a grade depends on that participation. A student gave an example of this when she said the following:

This semester I took a class and $25 \%$ of the whole grade belonged to participation ... and the whole semester even though the professor knows my name he does not ask me question because he knows I'm an international student and he knows oh this student, maybe she does not want to answer the question because she has an accent or she doesn't know the answer, I don't want to make her embarrassing like that...

This indicates that the effort by the professor to not single out this international student during class actually excluded the student from an essential classroom activity by not asking her questions, which at the same time was an impediment to earning $25 \%$ of her final grade. This experience exemplifies the power of stereotypes in the lives of people of color as the professor used his power in class to apply the stereotype of Chinese students not wanting to speak and participate in class.

Some of the participants indicated a high level of stress linked to speaking in class, specifically when expressing their own opinion or answering questions. A student expressed

... for any question if the teacher just asks your name and ask you to answer it and then sometimes you didn't pay attention to the class and then maybe you just don't know the answer it's kind of awkward and embarrassing.

Her level of stress linked to the public shame of not being able to answer a question during class appeared to be high. This same student later said that it is very difficult for Chinese students to participate in class because of timing and being able to express their own opinions in English quickly to stay on track with the speed of classroom discussion.

\section{Perceptions of the way American faculty and students perceived Chinese students}

Perceptions of faculty. Participants' perceptions were divided when they discussed the way they think American faculty members perceive Chinese international students. Some participants thought instructors have a good perception of Chinese students. Some of them said professors think Chinese students are "hardworking" and that they see the value of Chinese students in American universities. Other participants said that faculty members treat Chinese students the same way they treat American students. On the other hand, the majority said faculty members do not have a positive perception of Chinese students. One participant suggested that instructors profile Chinese students by saying:

I even talked to one of the professors who often catches Chinese students [cheating] and he said that when he is giving an exam, he specifically watch them [Chinese students] if 
they are in a cluster, they watch them very closely. I feel like they have some sort of profile of Chinese students specifically in the cheating part.

To support this idea, another student talked about an experience she had in one of her classes where there was assigned seating and two Chinese students happened to be seating next to each other. In that instance, the professor asked the students in front of the entire class to show identification because he thought they were not supposed to be there, in spite of his own assigned seating. The student perceived this action as discrimination because there were a number of American students seated next to each other, and they were not asked to show their identification, an effective illustration of the double consciousness created by practical racism.

Similarly, one other participant questioned the way some faculty members interact with Chinese students. The participant provided the following example:

....after my observation, the other students [American] talk to her [professor] and she is kind of smiling, but when, yesterday, I talk to her, and my group mates as well, and then all my group mates are Chinese as well, and then we try to talk to her and then she is having a bad mood. So I don't know if it is because yesterday she doesn't have a good mood or she has a hard time or hard day or she just don't like me or my group mates.

The student tried to explore other reasons why the professor would not act the same way with American students and with the student's group of Chinese students, such as having a bad day or a bad mood. The student's struggle to make sense of the professor's bias illustrates an internal conflict on the part of the student. It can be argued that these experiences create the perfect environment for Chinese international students to start experiencing an internal conflict of double consciousness.

Perceptions of American students. Only two students thought American students had a favorable perception of Chinese students. One of the students first mentioned that American students are very friendly and that he thought they think the same of Chinese students. The majority of students interviewed thought that American students had either a negative perception of Chinese students or two opposite extreme perceptions. Five participants remarked that American students may have a negative perception of Chinese students due to problematic experiences with teamwork. All of the participants that mentioned teamwork were business majors, where an emphasis is placed on teamwork. One student said, "American students get frustrated because Chinese students cannot express their ideas." Another student mentioned that during group presentations, the team gets points off from the grade if there is no eye contact with the public, which according to the student, is a problem for many Chinese students; another example of an environment that engenders an internal double-consciousness conflict.

Students also brought up some difficulties faced by Chinese students while participating in teamwork or discussions and how these difficulties affect the American students' perceptions of Chinese international students. One of the participants shared:

I feel like they [American students] have bad experience with team work, especially communications class, I think they can tell that they [Chinese] are kind of lagging off, in terms of, not because they don't have opinions, but they cannot say it fast enough. 
This student attributed overall perceptions of American students to difficult teamwork experience with Chinese students. She added the following:

They [Chinese students] don't know the right time to cut people off, the right time to jump in. That takes a lot of culture and a lot of experience to ask the right question at the right time, to cut people off at the right time, to jump in at the right time.

It seems that the student shared this observation in an effort to explain why American students had negative experiences with Chinese international students. It also seemed that the student attributed a lack of culture and experience to Chinese international students making them responsible for the American students' negative experiences.

\section{Double Consciousness}

A pattern of what can be referred to as double consciousness was suggested throughout the interviews. The students interviewed for this study showed some signs of double consciousness by identifying with Chinese international students, but also by making an effort to disassociate themselves from characteristics shared by Chinese students, which might be perceived as negative, according to the participants. This disassociation is consistent with Du Bois' concept of double consciousness and the conflict between two identities. One student identified himself as "Americanized" because he asked too many questions during class, while two other students started to describe themselves with opposite and more American-acceptable characteristics than their Chinese counterparts when asked about the way they thought American faculty or students perceived Chinese students.

The conflict of the identities of being Chinese and being "Americanized" became stronger particularly when speaking about classroom practices that were perceived as negative by American faculty and students. For example, one participant said that she shares examples from China during her classes all the time. This supported her view of being more "Americanized," as she described it, by speaking and participating in class often. When I asked for a specific example, she struggled and was not able to provide one, despite being in college for four years at the time of the interview. Regarding these conflicting identities, another participant expressed how she did not feel part of the group when students would raise their hands to answer questions in class.

Perceptions of Chinese international students about academic integrity also played an important role in the conflict of identities. All participants disassociated themselves from behaviors related to academic integrity violations, but accepted that it is a widely known stereotype of Chinese international students held by American faculty and students. This illustrates the power of the racial stereotypes in the lives and thoughts of people of color, in this case, Chinese international students.

\section{Conclusion}

The perceptions of Chinese international students about their classroom experiences in the United States were very revealing. While most of them preferred the American classroom practices over practices in China, their perceptions about the way American students and faculty perceived them were conflicting. The majority of participants appreciated a "more active" classroom setting, as some of them identified the typical U.S. classroom. Some of the 
characteristics that were identified as positive were the flexibility in the classroom setting and the collaboration with peers. On the other hand, practices that were perceived as culturally insensitive, such as activities that required specific knowledge about American culture, were identified as negative by participants.

The majority of the students agreed that American faculty members often do not have favorable perceptions of Chinese international students. Profiling and attributing characteristics such as cheating and unwillingness to participate in class were common examples among participants' illustrations. At the same time, some participants expressed that American students had negative perceptions of Chinese students mostly based on their experiences working in groups with Chinese students and their lack of contribution to group projects.

Consistent with some of the literature published about the experiences of Asian students in the U.S. (Chu \& Kim, 1999; Hsieh, 2007; Kim, 2012), Chinese international students in this study also struggled with identity. The concept of double consciousness helps to illustrate the internal identity conflict of being Chinese and being "Americanized." Inconsistencies in their examples suggest they may identify with a specific identity, Chinese or "Americanized", but provide examples of the opposite. As predicted by Dickson (1992), the power of stereotypes in the lives of people of color, in this case Chinese international students; encounters with practical racism; and the internal conflict of identities all played an important role in the manifestation of this double consciousness.

An important finding of this research is how the power of assumptions shapes perceptions in a classroom setting. Assumptions were made by Chinese international students themselves, as well as American faculty and students, according to participants. Some of the assumptions made by Chinese international students included how they perceived the unwillingness of American students to work in teams with Chinese international students and stereotypes of Chinese international students linked to academic integrity violations attributed by professors. Regarding faculty, some participants believed faculty made assumptions about the unwillingness of Chinese international students to participate in class and profile students in issues of cheating and academic dishonesty. Participants also believed that American students made some assumptions about Chinese international students including the inability to contribute to group projects, which is consistent with the assumptions of Chinese international students about group work. This study highlights how embedded cultural assumptions often determine how we perceive others as well as ourselves, especially in a classroom setting, and how this affects our social interaction with others.

The study will add to the limited published literature available about Chinese students' perspectives of their classroom experiences in the U.S. The results of this study suggest a sense of urgency to provide more resources to faculty in the form of training and professional development to help them create classroom practices that are inclusive for all students and to promote collaboration between Chinese international students and American students. It is also important to create awareness of the effects of cultural assumptions in the higher education classroom setting. Similarly, further research about the experiences of Chinese students is needed, especially with a focus on issues of racism and inequity. Also, future research and interviews with U.S. faculty, students and administrators about Chinese international students could provide a better understanding of the experiences of this specific group of students, the largest group of international students in the U.S. 


\section{REFERENCES}

Adell, S. (1994). Double-consciousness/double bind: Theoretical issues in twentieth-century black literature. Chicago, IL: University of Illinois Press.

Chen, J., \& Lu, C. (2006). Does China's middle class think and act democratically? Attitudinal and behavioral orientation toward urban self-government. Journal of Chinese Political Science, 11(2), 1-20.

Choudaha, R., Chang, L., \& Kono, Y. (2013). International Student Mobility Trends 2013: Towards Responsive Recruitment Strategies. New York, NY: World Education Services. Retrieved from www.wes.org/RAS

Chu, S., \& Kim, J. (1999). Comparison of the perceptions of classroom participation among Asian and non-Asian design students. Multicultural Education, 7(2), 21-4.

Dayal, S. (1996). Diaspora and double consciousness. The Journal of the Midwest Modern Language Association, 46-62.

Dickson, B. (1992). W.E.B. Du Bois and the idea of double consciousness. American Literature, 64 (2), 299-309.

Du Bois, W. E. B. (1897). Strivings of the Negro people. Atlantic Monthly Company, 80, 194.

ETS (2014). Test of English as a Foreign Language (TOEFL). Retrieved from http://www.ets.org/toefl

Heggins, W., \& Jackson, J. (2001). Understanding the collegiate experience for Asian international students at a Midwestern research university. College Student Journal, 370391.

Hsieh, M. (2007). Challenges for international students in higher education: one student's narrated story of invisibility and struggle. College Student Journal, 379-391.

Holmes, P. (2006). Problematising intercultural communication competence in the pluricultural classroom: Chinese students in a New Zealand university. Language and Intercultural Communication, 6(1), 18-34.

Institute of International Education. (2013). Open Doors 2013: Report on international education exchange. Washington, DC: National Press Club.

International Comparative Higher Education Finance and Accessibility Project (2009). A Brief Description of the Chinese Higher Education System. Retrieved from http://gse.buffalo.edu/org/inthigheredfinance/files/Country_Profiles/Asia/China.pdf

Kim, J. (2012). The birth of academic subalterns: How do foreign students embody the global hegemony of American universities? Journal of Studies in International Education, 16(5), 455-476.

Lee, C. D. (1990). How shall we sing our sacred song in a strange land? The dilemma of a double consciousness and the complexities of an African-centered pedagogy. Journal of Education, 172(2), 45-61.

Liberman, K. (1994). Asian student perspectives on American university instruction. International Journal Intercultural, 18(2), 173-192.

Liu, X., Elston, F., \& Zhou, P. (2013). Comparing research on Chinese students study abroad decision-making: China-based versus overseas-based perspectives. In Proceedings of the 23rd International Business Research Conference (pp. 1-13). World Business Institute.

Major, E. (2005). Co-national support, cultural therapy, and the adjustment of Asian students to an English-speaking university culture. International Education Journal, 6(1), 84-95.

Merriam, S. B. (2009). Qualitative research: A guide to design and implementation. New York: John Wiley \& Sons. 
Valdez, G. (2015). International Students Classroom Exclusion in U.S. Higher Education (Unpublished doctoral dissertation). The University of Arizona, Tucson, AZ.

Vygotsky, L. S. (1978). Mind in society: The development of higher psychological processes. Cambridge, MA: Harvard University Press.

Wan, G. (1999). The Learning Experience of Chinese Students in American Universities: A Cross-Cultural Perspective. College Student Journal, 35(1), 28-44.

Wang, L., \& Byram, M. (2011). But when you are doing your exams it is the same as in ChinaChinese students adjusting to western approaches to teaching and learning. Cambridge Journal of Education, 41, 407-424.

Zhou, Y., Knoke, D., \& Sakamoto, I. (2005). Rethinking silence in the classroom: Chinese students' experiences of sharing indigenous knowledge, International Journal of Inclusive Education, 9(3), 287-311, doi: 10.1080/13603110500075180

\section{Appendix 1}

\section{Interview Questions for Chinese Students}

- How would you describe an American classroom compared to China?

- Do you talk in class?

- How much do you talk in class per week compared to U.S. students? Why?

- What is your opinion about classroom discussion?

- Do you feel you get enough instructions and direction from your professor? Can you give me an example?

- Do you go to your professors' office hours? How often? What do you talk about?

- Do you participate in class?

- Can you describe different classroom activities in which you participate?

- Can you identify a classroom activity in which you feel the most comfortable? Why?

- During classroom discussion, do you share examples from China or your own experience? Can you give me an example?

- How would you describe your interaction with students when you are working in small groups?

- Have you given an oral presentation? What is your opinion about oral presentations?

- How do you think American students/faculty view Chinese students in a classroom setting? Can you give me an example?

- In your opinion, who are the students who get the most attention in class? Why?

- Think of your favorite class so far. Can you tell me why that was your favorite class?

- How many hours per week, outside of classroom, do you work on homework or prepare for class? Can you give me some examples?

\section{About the Author}

GABRIELA VALDEZ is a doctoral candidate (International Education \& Global Perspectives/Higher Education Management) at the University of Arizona. She is also an academic advisor for pre-business majors and international internships program at the University of Arizona. E-mail: gvaldez@eller.arizona.edu 